\title{
CBL in Medical Education Effective Learning Methodology than PBL
}

\section{Montosh Chakraborty ${ }^{1}$, Shivakrishna Gouroju ${ }^{* 2}$, Pinki Garg ${ }^{3}$, Karthikeyan P ${ }^{4}$, Prerna Singh 2.}

${ }^{1}$ Asst.prof. Department of Biochemistry, Andaman and Nicobar Islands Institute of M edical Sciences, Port Blair, India.

${ }^{* 2}$ Tutor in Department of Biochemistry, Andaman and Nicobar Islands Institute of M edical Sciences, Port Blair, India.

${ }^{3}$ Asst.prof. Department of Biochemistry, NDM C M edical college, Delhi, India.

${ }^{4}$ PG trainee, Department of Biochemistry, M aulana Azad M edical college, New Delhi, India.

\section{ABSTRACT}

\begin{abstract}
The conventional teaching and learning methods in medical education yearns for a change. The newer and effective small group interactive teaching methodologies are being looked into. Problem based learning and case based learning modules were taken into consideration in this study. Although PBL is student centred but it lacks able guidance of the teacher involved and effective participation of all the students. The deficiencies encountered in PBL are taken care of in case based learning study. It is a guided enquiry approach where the teacher plays a vital role in the preparation of the case based problem, organizing the CBL session under his guidance and providing constructive and relevant information during the sessions. Students are the speakers and presenters. Generally, most of the studies refer to the advantages of CBL and PBL in regard to traditional teaching. This study compares the learning effectiveness amongst the two approaches. A total of 126 first year medical students were included in the study. Students were divided into two groups such that both the groups have similar academic knowledge. The effectiveness of the teaching methodologies was reflected in the better performance of the students in the evaluation tests conducted after the said sessions. Both the groups performed better in the evaluation tests conducted after the PBL and CBL session. But the performance was better in the group which attended CBL on the same topic. The difference in the mean marks of the two groups being statistically significant. . However it seems important to develop more consistent research in this field, namely, longitudinal studies with larger samples.
\end{abstract}

KEY WORDS: Case Based Learning, Problem Based Learning, medicalEducation.

Address for correspondence: Shivakrishna Gouroju, Tutor in Department of Biochemistry, Andaman and Nicobar Islands Institute of M edical Sciences, Port Blair, India.

E-M ail: phdbiochemshiv@gmail.com

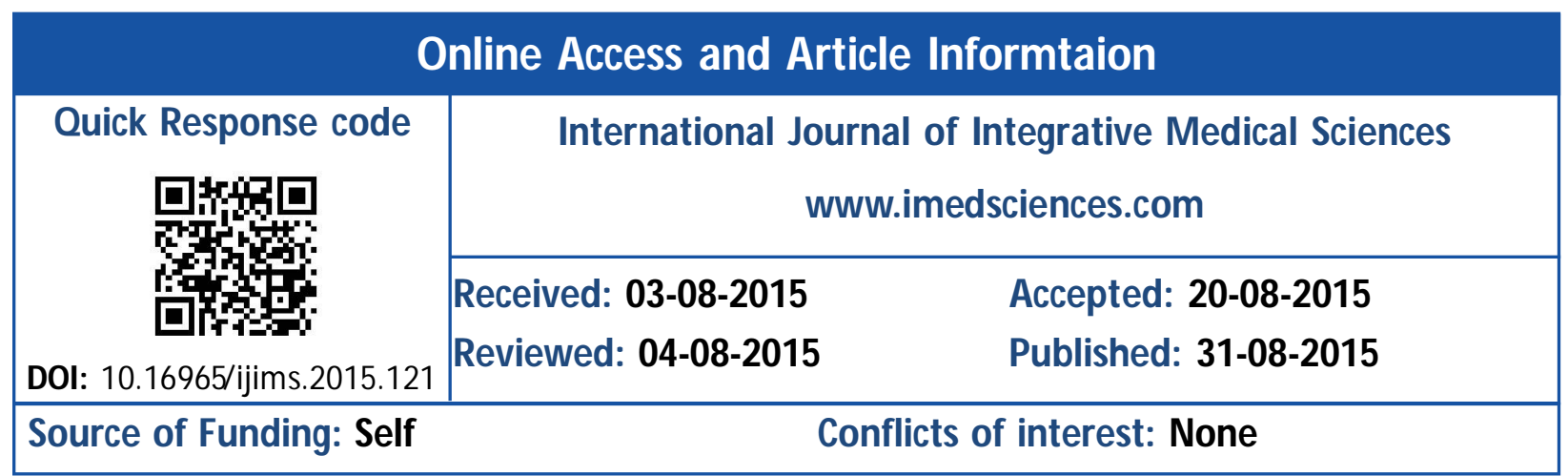

\section{INTRODUCTION}

The medical world is abuzz with the idea of reforming the medical education system. The conventional mode of education needs an improvisation so as to impart the expected qualities in the students. For e.g. to inculcate the problem solving ability, making deductive conclusions and the habit of self study in their life. Although there is no dearth of knowledge resources but the acquisition of the knowledge along with the technical expertise and its timely application in the present health scenario is the 
need of present medical education system. The sea of information and knowledge around a student doesn't mean the student has developed the concepts of the subject or he knows how and when to apply it for patient care. Efforts are being made to bridge this gap by the development of various modes of interactive teaching programmes like interactive lecture, problem based learning, and case based learning, tutorials, and interactive seminar sessions and so on. It has been seen that when we work and learn in small groups with interactive sessions, it helps to foster the right spirit and in understanding the subject in a better manner. This in turn leads to confident application of the knowledge acquired. Learning from problems is a condition for human existence. In 1969, PBL was introduced to medical curriculum and has been endorsed as an educational strategy [1]. The findings of this methodology can be traced back to Dewey [2]. It is an important student centric method where the knowledge is better retained with clinical context $\&$ integration from the relevant disciplines.

PBL proponents argue that PBL methods encourage lifelong learning, simulate clinical practice, encourage curiosity, and create a broader understanding of the complexity of medicine $[3,4]$. PBL detractors argue that the PBL process is time inefficient, frustrating for time pressured medical learners, and often leads to erroneous conclusions [5]. Additionally, there is little guarantee that the students will learn how to apply the knowledge necessary for clinical practice in the absence of appropriate clinical direction and as such the presence and expertise of the faculty is wasted if it is not harnessed in more than a passive manner. Also, as PBL requires interactive participation, the students having poor communication skills are likely to lag behind and dominated by the aggressive speakers. Therefore we look for another small group interactive teaching programme so as to provide an alternative to PBL.

Case based learning (CBL) is an educational paradigm closely related to the more common PBL. CBL's main traits are derived from PBL e.g. a case, problem, or inquiry is used to stimulate and underpin the acquisition of knowledge, skills, and attitudes [6]. However, when learners begin to explore tangents, the facilitators use guiding questions to bring them back to the main learning objective. Hence CBL uses a guided inquiry method and provides a structured smallgroup session unlike PBL which is an open inquiry approach where facilitators play a minimal role and do not guide the discussion, even when learners explore tangents $[7,8]$. Thus, CBL can be summarized as a form of small group learning with the help of case scenarios in the presence of active facilitators. Since the process is case based discussion and fosters deductive reasoning, it can be expected to be a better answer to instill the right spirit amongst the medical students. Additionally, students prepare in advance for the session, and they may ask questions to the local experts during the session which means the facilitators also need to come prepared for the class. Further, CBL proponents argue that CBL helps focus the learners on the key points of a clinical case, and encourages a structured approach to clinical problem-solving. They argue that the facilitators can correct or modify the incorrect assumptions of the learner, which usually does not happen in PBL. Facilitators can moderate the influence of louder, more contributory students and allow everybody to participate in a fair and equal manner. The implementation and assessment of $\mathrm{CBL}$ is well documented in various levels of biomedical sciences such as Medicine $[9,10]$, Geriatrics [11], Nursing [12], Therapeutics and Medicinal Chemistry (13), Pharmaceutics (14), Obstetrics and Gynecology [15], Anatomy [16], Orthodontics [17] and Allied Health [18]. CBL detractors argue that providing answers to the questions in PBL or even guiding those makes them lax and reluctant to search for the answers. Also, intensive faculty training is required to carry out CBL in a well coordinated manner otherwise it will just become another lecture class. They feel that CBL encourages a spoonfeeding mentality of learners, in which they always expect their peers or teachers to have the correct answers. The acceptability of any model of teaching no doubt relies on the acquisition of knowledge along with the holistic development of the medico with the instillation of right attitude towards their work. 
The knowledge enhancement part can be evaluated by the assessments done after the sessions. In this study, an effort was made to estimate the effectiveness of CBL as a knowledge enhancement tool in comparison to PBLmethod.

\section{MATERIALS AND METHODS}

The study was conducted in the Department of Biochemistry, Maulana Azad M edical College, New Delhi, India. The program scheduled was traditional lecture class, PBL class and CBL class. 126 first year M BBS students were included in the study. We conducted an evaluation test of 20 marks multiple choice questions before the conventional lecture class and after lecture class with the same question paper. Based on the marks obtained in the exams, we divided the total participants into 2 equal groups and were sex matched such that the means of two group are almost equal (Table no.3). Group-I with 63 students (31 females, 32 males) attended PBL class and group-II consisting of 63 students ( 32 females and 31 males) attended CBL class. After that an evaluation test was carried out for both the groups with the same question paper. The results were given on the next day of the program.

\section{RESULTS AND TABLES}

A total of 126 learners including $63(50 \%)$ females and $63(50 \%)$ male students were part of the study. The learners reveal that the CBL system helps to develop their problem solving skills, sharpen up analytic skills and it also helped to develop a better concept of the subject. All these led to arouse their interest in the subject which is manifested in their academic performance. Their academic improvement was measured by their score in the evaluation tests conducted after the PBL and $\mathrm{CBL}$ session. After the PBL class, the learners
Table 1: Shows the percentage (\%) of marks obtained in the evaluation test before and after theory.

\begin{tabular}{|c|c|c|}
\hline & Before theory & After theory \\
\hline Total \% & 43.49 & 57.66 \\
\hline Female \% & 41.75 & 56.35 \\
\hline Male \% & 45.24 & 58.97 \\
\hline
\end{tabular}

Table 2: Shows the MEAN and SD of total participants' marks before and after theory.

\begin{tabular}{|c|c|c|}
\hline & MEAN & SD \\
\hline Before theory & 8.7 & 2.03 \\
\hline After theory & 11.53 & 1.83 \\
\hline
\end{tabular}

Graph 1: SCATTER PLOTS showing the range of marks obtained in the evaluation test conducted before and after theory.

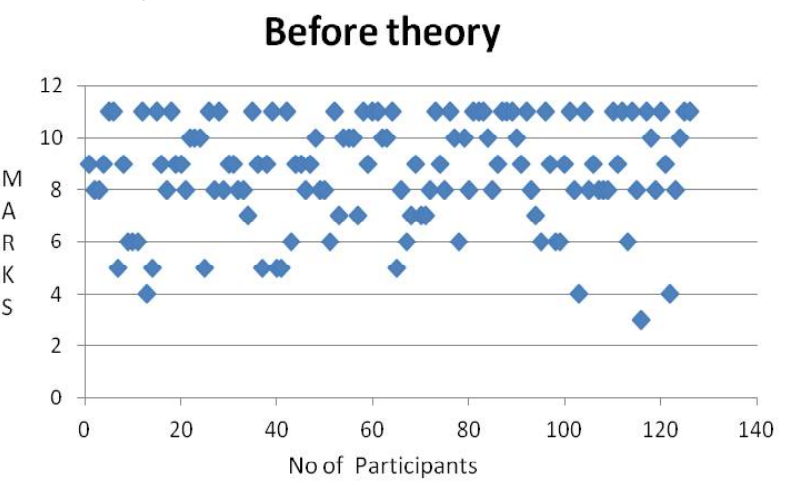

After theory

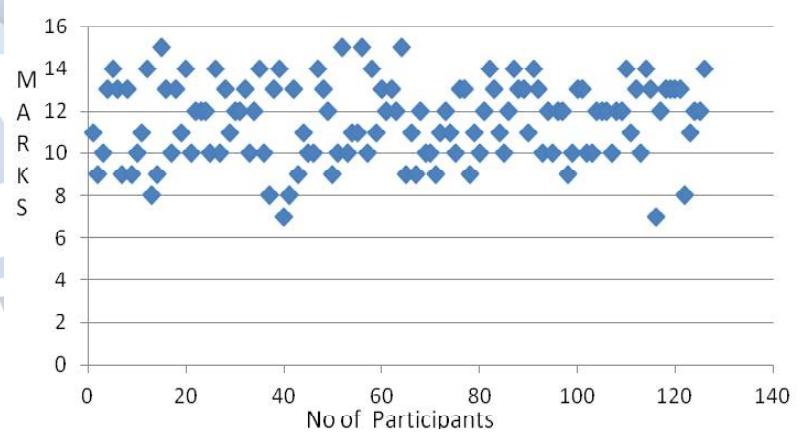

Table 3: shows the MEAN and SD of marks obtained before theory, after theory, post PBL and post CBL in Group-I and II.

\begin{tabular}{|c|c|c|c|c|}
\hline & \multicolumn{2}{|c|}{ Group-I (No-63) } & \multicolumn{2}{c|}{ Group-II (No-63) } \\
\cline { 2 - 5 } & MEAN & SD & MEAN & SD \\
\hline Before theory & 8.7 & 2.03 & 8.7 & 2.04 \\
\hline After theory & 11.56 & 1.97 & 11.51 & 1.7 \\
\hline Post PBL & 14.46 & 1.4 & & \\
\hline Post CBL & & & 15.62 & 1.49 \\
\hline
\end{tabular}

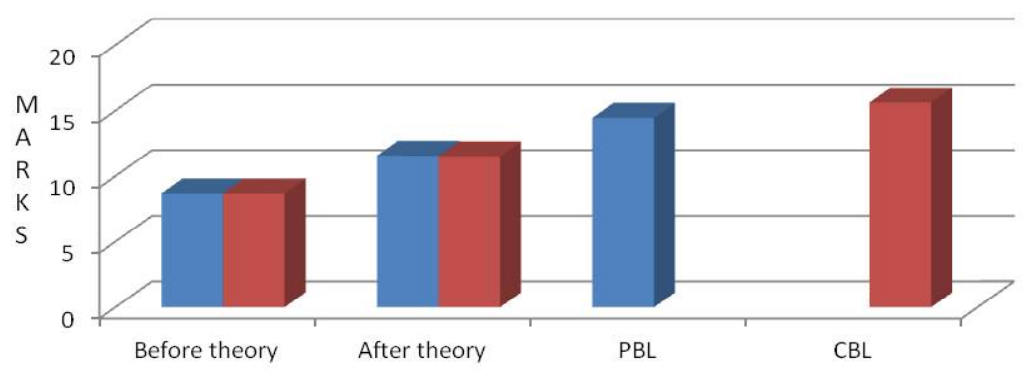

Graph 2: Bar diagram showing the $M E A N$ and SD of marks obtained Before theory, After theory, post PBL and post CBL in Group 1 and 2. 
scored $72.30 \%$ in the evaluation test whereas it was $43.49 \%$ before theory and $57.78 \%$ after theory. After CBL, attended by the second group, the learners scored $78.10 \%$ which was $43.49 \%$ earlier (before theory) and $57.54 \%$ after theory. Group-II which attended CBL class showed higher percentage of marks than Group-I.

Table 4: shows the $p$-values of marks obtained in the evaluation tests in Group-I and II.

\begin{tabular}{|c|c|c|}
\hline & & p-value \\
\hline \multirow{2}{*}{ Group-I } & Post PBL Vs Pre Theory & $0.00 *$ \\
\cline { 2 - 3 } & Post PBL Vs post Theory & $0.00^{*}$ \\
\hline \multirow{2}{*}{ Group-II } & Post CBL Vs pre Theory & $0.00^{*}$ \\
\cline { 2 - 3 } & Post CBL Vs post Theory & $0.00 *$ \\
\hline
\end{tabular}

*Statistically Significant

Table 5: shows the p-value of the marks obtained by Group-I Vs Group II.

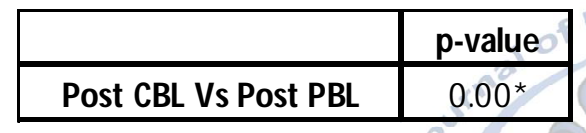

*Statistically Significant ting, informative and clinical oriented but is also able to fetch better marks for the students in the examinations and assessment tests.

The newer innovative small group interactive teaching is a better process to learn the medical subject than traditional teaching. Some academicians are of the opinion that the most important purpose of such small group interactive teaching methods is to provide a clinical context for the acquisition of knowledge, rather than to solve the problem $[22,23]$. Students who have significant deficiencies in expressing ideas or communication skills are likely to be unsuccessful in a PBL program, as PBL requires the ability to process and discuss ideas and learn independently. It thus seems likely that with a guided inquiry approach as in $\mathrm{CBL}$ these students might find the problem solving exercises interesting and this might as well improve their academic performance. In this study of ours, we have tried to evaluate the academic effectiveness of PBL and CBL in the form of assessment tests performed after the said sessions. Our form of CBL, an adaptation of that used at UCLA differs from classical CBL in the following major ways:

1. Learning objectives for the session, (these are a subset of objectives from those of the place in the Curriculum in which the CBL resides), are provided to the students before they see the case. However, students do not see the actual case until the CBL session begins.

2. Information in the form of lectures and/or other material is made available to the students prior to the CBL session. This allows some advance preparation to take place before the students see the case. This information will not be enough for the students to master all or possibly even any of the learning objectives during $\mathrm{CBL}$, but it will allow the students to have some knowledge upon which to build during CBL. It is to be noted that although each CBL module is based on a case, it does not necessarily need to be a clinical case. A basic physiology problem could easily be used as the basis for a $C B L$ case. The use of various innovative teaching methods for imparting undergraduate medical education appears to improve the teaching- learning process for both the teacher students' attention when it is not only interes- 
as well as for the students. In the traditional didactic lectures stress is given on teaching alone, so it puts the learner on a passive role. CBL enhances the development of lateral thinking and clinical co-relation. The teaching of biochemistry in medical college is mostly focused on the chemical structure and metabolism of biomolecules [24]. The clinical aspect and relevance of these biomolecules have become a very important part of the teaching module nowadays. The knowledge gained by this traditional method is hardly retained till the clinical teaching starts in the later years. The use of innovative teaching-learning methodology involving CBL can help the students to understand the molecular basis of life in health and disease. Clinical correlation of this knowledge makes the subject interesting and is better retained. Academicians like Surapaneni [25] reported CBL methodology to be a valuable tool in biochemistry. The implementation of $\mathrm{CBL}$ in medical education will prepare students as competent primary care physicians. CBL also promotes active participation of the students in learning biochemistry in the context of clinical case and it also helps to improve the diagnostic skills by deductive reasoning [25]. It also overcomes the disadvantages pointed out in PBL as its a guided enquiry approach. The students can participate in a fair manner in the discussion. Students as well as facilitator prepare for this session. The vast scope of interaction and active role of each participant makes CBL more meaningful. M ost of the students appreciated this aspect of CBL. This observation is similar to that of M eyer et al [24]. Interactive sessions make students curious, attentive and active participants [26]. CBL also helps to build a concept of the particular topic which is not possible during routine theory classes. This observation is similar to that of Singh et al [27].

The key to case-based instruction is to build up cases that are clear and realistic and encompass all the teaching points the instructor wishes to convey. Constructing such cases can be time consuming. Studies have shown that relative to conventional teaching, case-based instruction significantly improves student retention [28], reasoning and problem-solving skills [29], higher- order skills on Bloom's taxonomy [30], the ability to make objective judgments [31], the ability to identify relevant issues and recognize multiple perspectives [32], and aware- ness of ethical issues [33]. Lundeberg and Yadav [34] carried out a meta-analysis and concluded that case based learning have a positive impact on faculty and student attitudes, class attendance, and faculty perceptions of learning outcomes.

Major findings and final remarks: Our study indicates that the use of $C B L$ and PBL is well documented in M edical Education. The subjects in basic sciences can be associated with these approaches. This result may be explained by the large amount of literature being published, and because other medical areas like Allied Health and Pharmacy, represent a younger existence when compared with traditional Medical education. While addressing the effectiveness of $\mathrm{CBL}$ and $\mathrm{PBL}$ as learning vehicles in comparison to traditional didactic lectures, the study also compares CBLand PBL as an effective learning method by focusing on the academic outcomes of students. From the present study it can be concluded that CBL can be used as an innovative teaching method for better retention of knowledge, clarity of subject and application of biochemistry in medicine. This innovative teaching-learning methodology is student centered and achieves greater learner satisfaction.

\section{REFERENCES}

[1]. Neufeld VR, Woodward CA, MacLeod SM. The M cM aster M .D. programme: a case study of renewal in medical education. Acad M ed 1989;64:423-32.

[2]. Dewey, J. EBook. 852. Democracy And Education. 2008:July 26.

[3]. Barrows HS. A taxomony of problem-based learning concepts. Med Educ. 1986;20:481-486.

[4]. Maudsley G. Do we all mean the same thing by problem-based learning? A review of the concepts and formulation of the ground rules. Acad Med. 1999;74:178-185.

[5]. Slavin SJ, Wilkes MS, Usatine R. Doctoring III. Innovations in education in the clinical years. Acad Med. 1995;70:1091-1095.

[6]. Schmidt HG. Assumptions underlying self-directed learning may be false. Med Educ 2000;34:243-5.

[7]. Distlehorst LH, Dawson E, Robbs RS, Barrows HS. Problem-based learning outcomes: the glass halffull. Acad M ed 2005;80:294-9.

[8]. Srinivasan M, Wilkes, M, Stevenson, F, Nguyen, T, Slavin, S: Comparing Problem-Based Learning with Case-Based Learning: Effects of a Major Curricular 
Shift at Two Institutions. Acad M ed. 2007;82:74-82.

[9]. Srinivasan, M., Wilkes, M., Stevenson, F., Nguyen, T., $\&$ Slavin, S. Comparing problem- based learning with case-based learning: effects of a major curricular shift at two institutions. Academic Medicine: Journal of the Association of American Medical Colleges, 2007;82(1):74-82.

[10]. Jamkar, A. V., Burdick, W., M orahan, P., Yemul, V. Y., Sarmukadum, \& Singh, G. Proposed model of case based learning for training undergraduate medical student in surgery. Indian Journal of Surgery, 2008;69(5):176-183.

[11]. Struck, B. D., \& Teasdale, T. A. Development and evaluation of a longitudinal Case Based Learning (CBL) experience for a geriatric medicine rotation. Gerontology \& Geriatrics Education, 2008;28(3):105-114.

[12]. Yoo, M .-S., Park, J.-H., \& Lee, S.-R. The effects of casebased learning using video on clinical decision making and learning motivation in undergraduate nursing students. Journal of Korean Academy of Nursing, 2010;40(6):863-871.

[13]. Ives, T., Deloatch, K. H., \&lshaq, K. S. Integration of Medicinal Chemistry and Pharmacotherapeutics Courses: A Case-Based, Learner-Centered Approach. American Journal of Pharmaceutical Education, 1998;62(4).

[14]. Romero, R., Erikson, S., \& Haworth, I. A Decade of Teaching Pharmaceutics Using Case Studies and ProblemBased Learning. American Journal of Pharmaceutical Education, 2004;68(2).

[15]. M assonetto, J. C., M arcellini, C., Assis, P. S. R., \& de Toledo, S. F. Student responses to the introduction of case-based learning and practical activities into a theoretical obstetrics and gynaecology teaching programme. BM CM edical Education, 2004;4(1): 26.

[16].Peplow, P. V. Self-directed learning in anatomy: incorporation of case-based studies into a conventional medical curriculum. Medical Education, 1990;24(5):426-432.

[17]. Engel, F. E., \&Hendricson, W. D. A case-based learning model in orthodontics. Journal of Dental Education, 1994;58(10):762-767.

[18].M cKay, J., \& White, P. Case-based Learning Introduced into an Allied Health Programme. International Journal of Learning, 2003;10.

[19]. Dolmans DH, De Grave W, Wolfhagen IH, van der Vleuten CP. Problem-based learning: future challenges for educational practice and research. Med Educ 2005;39: 732-41.

[20]. Carrera LI, Tellez TE, D'Ottavio AE: Implementing a problem-based learning curriculum in an Argentinean medical school: implications for developing countries. Acad M ed 2003;78:798-801.
[21]. Schmidt HG. Assumptions underlying self-directed learning may be false. Med Educ 2000;34:243-5.

[22]. M assey RU. Problem-based learning: a better way? Conn Med 1994;58:753.

[23]. Norman, GR and Schmidt HG. The psychological basis of problem-based learning: a review of the evidence. Acad Med, 1992;67:557-65.

[24]. Meyers C, Jones TB. Case studies, In: Promoting active learning: Strategies for the College Classroom. San Francisco, CA: Jossey-Bass, 1993; p.103-119.

[25]. Surapanemi KM. The effect of integrated teaching with case based learning (CBL) in the biochemistry of undergraduate medical curriculum. Journal of Clinical and Diagnostic Research, 2010; 5:30583063.

[26]. Margetson D. Beginning with the essentials: why problem based learning begins with problems. Education for health. 1996;9:61-69.

[27]. Singh PR, Bhatt R. Introduction of case based learning for teaching anatomy in a conventional medical school. J AnatSoc India, 2011;60:232-235.

[28]. Fasko, D. and Louisville, KY. Case studies and method in teaching and learning. Paper presented at the annual meeting of the Society of Educators and Scholars, 2003.

[29]. Levin, B. The influence of context in case-based teaching: Personal dilemmas, moral issues or real change in teachers' thinking? Paper presented at the annual meeting of the American Educational Research Association.1997.

[30]. Gabel, C. Using case studies to teach science. Paper presented at the annual meeting of the National Association for Research in Science Teaching, Boston.1999.

[31]. Dinan, F. Chemistry by the case. Journal of College Science Teaching 2002;32(1):36-41.

[32]. Lundeberg, M., B. Levin, and H. Harrington. Who learns what from cases and how? The research base for teaching and learning with cases. M ahwah, $\mathrm{NJ}$ : Lawrence Erlbaum Associates. 1999.

[33]. Lundeberg, M., K. M ogen, M. Bergland, K. Klyczek, D. Johnson, and E. M acDonald. 2002. Fostering ethical awareness about human genetics through multimedia-based cases. Journal of College Science Teaching. 2002;32(1):64-69.

[34]. Lundeberg, M.A., and A. Yadav. Assessment of case study teaching: Where do we go from here? Pts. 1 and 2. Journal of College Science Teaching. 2006;35 (5):10-13;35 (6):8-13.

How to cite this article: M ontosh Chakraborty, Shivakrishna Gouroju, Pinki Garg, Karthikeyan P, Prerna Singh. CBL in M edical Education Effective Learning Methodology than PBL. Int J Intg Med Sci 2015;2(8):145-150. DOI: 10.16965/ijims.2015.121 